\title{
Vier sleutelareas van die onderwys in 'n nuwe staatkundige bedeling in Suid-Afrika
}

\author{
H.B. Kruger
}

Fakulteit Opvoedkunde

Potchefstroomse Universiteit vir $\mathrm{CHO}$

POTCHEFSTROOM

\begin{abstract}
Quite a few changes have occurred in South Africa since 2 Febniary 1990 - even in the field of education. The greatest changes in education, however, still lie ahead. Thus the present fifteen education departments will probably be replaced by one education system and regional departments.

A few important challenges for education include, inter alia, the financial situation, in which providing for the best possible education with the little money that is available, will have to be planned. In addition the rate of population growth is very high. A new education structure will make greater demands in regard to a heterogeneous school population and multicultural education. Education standards will also have to be maintained as far as certification and the professional quality of the teachers are concemed. In the meantime it remains imponant that education is still provided on the basis of sound educational principles - this includes education through the medium of the home language, the construction and maintenance of the spirit and character of the school, the continuation of the culture of the parental home in the school and the involvement and responsibility of parents in the education. These aims will have to be promoted purposefully.
\end{abstract}

\section{AGTERGROND}

Sedert 2 Februarie 1990 het daar in Suid-Afrika op politieke en maatskaplike terreine 'n reeks belangrike ontwikkelings plaasgevind. Oor die onderwys is heelwat uitsprake deur politieke rolspelers gemaak en standpunte oor 'n nuwe bedeling gestel. Die onderwysbegroting, en veral die verdeling daarvan tussen die huidige onderwysdepartemente, is aangepas. In die blanke onderwys het omtrent $96 \%$ van die skole by die model van staatsondersteunde skole ingeval, wat meebring dat die plaaslike ouergemeenskap die bedryfskoste en onderhoud van die skool vir sy rekening neem.

In die besprekings wat op verskillende vlakke deur die belanghebbende partye gevoer word, blyk dit dat daar 'n paar onderwysterreine is waar die probleme en uitdagings die sterkste aangevoel word. Dit is veral in die onderwys vir swartes waar die probleem die ernstigste is. Die huidige ontwrigting van die onderwys, die finansiële 
wanbesteding, wegbly-aksies deur leerlinge en onderwysers en die gedagte dat die onderwys gebruik moet word vir die bereiking van politieke doelwitte, dra alles by om die situasie te vererger. ' $n$ Kenner van onderwys vir swartes in Suid-Afrika, Hartshorne (1992: 334), sê trouens. "In the next three to five years, while the centre of the stage is taken up by political moves, black schooling will deteriorate and crumble even more rapidly."

Die doel met hierdie artikel is om vier van die belangrikste fokuspunte van die formele onderwys in die RSA uit te lig en te ontleed en om moontlike antwoorde, of minstens standpunte in verband hiermee te formuleer.

\section{DIE HUIDIGE ONDERWYSSTELSEL}

Die geskiedenis van die onderwys in Suid-Afrika is ten nouste met die maatskaplike en politieke ontwikkelinge verweef, maar die huidige situasie het sy beslag in die laaste paar dekades gekry.

Om die moontlike veranderings aan die onderwysstelsel in konteks te kan plaas word kortliks na die huidige situasie gekyk sover dit die verskillende onderwysdepartemente betref.

Die onderwys vir blankes is grootliks bepaal deur die Wet op Onderwysbeleid, (Wet 39 van 1967), soos gewysig, die Wet op Nasionale Beleid vir Algemene Onderwyssake, (Wet 76 van 1984) en die Wet op Onderwysaangeleenthede (Wet 70 van 1988). Die onderwys vir Kleurlinge en Indiërs word tans nog kragtens die Grondwet, (Wet 110 van 1983), gereël, terwyl die onderwys vir swart mense deur die Minister van Onderwys en Opleiding geadministreer word.

Die feit dat daar vyftien onderwysdepartemente in Suid-Afrika is (Du Plessis et al., 1990:3), word deur baie as onnodige duplisering en prolifirering van personeeldienste en onderwysfasiliteite beskou. Die Departement van Nasionale Opvoeding het kragtens die Wet op Nasionale Beleid vir Algemene Onderwyssake as oorkoepelende taak om beleid vir alle onderwysdepartemente te formuleer ten opsigte van norme en standaarde vir alle onderwysfinansiering, salarisse en diensvoorwaardes van personeel, professionele registrasie van onderwysers en norme en standaarde vir leerplanne en eksaminering en sertifisering van kwalifikasies. Onderwys vir blankes ressorteer onder die Departement van Onderwys en Kultuur (Administrasie: Volksraad) en word bedryf deur vier uitvoerende departemente - een vir elke provinsie. Kleurlingonderwys word behartig deur die Departement van Onderwys en Kultuur (Huis van Verteenwoordigers), Indiëronderwys deur die Departement van Onderwys en Kultuur (Raad 
van Afgevaardigdes), terwyl onderwys vir swartes deur die Departement van Onderwys en Opleiding behartig word. Daarbenewens is daar in elk van die state Transkei, Bophuthatswana, Venda en Ciskei onafhanklike onderwysdepartemente, asook'n eie departement vir elk van die ses selfregerende state.

Die onderwysdepartemente in Suid-Afrika word almal gefinansier uit die staatskas, terwyl die onderwys in die vier TBVC-state in 'n groot mate deur die Suid-Afrikaanse regering gesubsidieer word.

Die standaard van die werk wat deur die verskillende onderwysdepartemente gedoen word, is vir die afgelope dekades bepaal deur die Gemeenskaplike Matrikulasieraad wat die universiteits-toelatingseksamen beheer. Hierdie liggaam is tans in die proses om vervang te word deur die Suid-Afrikaanse Sertifiseringsraad.

\section{NUWE ONTWIKKELINGS}

Sedert 2 Februarie 1990 is standpunte oor staatkundige, maatskaplike en ekonomiese sake deur die verskillende partye gestel. Ook die toekoms van die onderwys is tans sterk in die kollig. Dit is trouens ' $n$ vraag of die onderwys nie 'n kernsaak is wat gehanteer en tot groot hoogte verhelder moet word voordat finale beslag aan 'n staatkundige model gegee word nie. Standpunte oor die finansiële pariteitsbeginsel, 'n totale nuwe onderwysstruktuur, die kurrikulum, en so meer, is reeds in openbare toesprake en in persverklarings deur die Nasionale Party, die African National Congress, die Inkatha Vryheidsparty, die Konserwatiewe Party en ander partye ingeneem. Alhoewel daar belangrike verskille tussen hierdie standpunte na vore kom, is daar 'n aantal aspekte van die onderwys wat as gemeenskaplik beskou kan word. Oor hierdie basiese sake bestaan daar by feitlik almal kommer: die finansiële haalbaarheid, die funksionering van 'n nuwe onderwysstruktuur, die handhawing van standaarde en ouerbetrokkenheid.

Dit is nodig om te kyk na die uitdagings wat op elkeen van hierdie terreine aan die regering, die onderwyskundiges en aan die deursneemens gestel gaan word.

\section{FINANSIËLE UITDAGINGS}

In Suid-Afrika (TBVC-state uitgesluit) was daar op 31 Maart 1992 'n totaal van 8374 564 (DNO, 1992:9) leerlinge vanaf graad 1/sub A tot st. 10 in die gewone openbare skole. Om vir al hierdie leerders se onderwys finansiële voorsiening te maak, verg toenemend groter bydraes uit die staatskas. 
Vier sleutelareas van die onderwys in 'n nuwe staatkundige bedeling in Suid-Afrika

Gedurende die afgelope aantal jare het die besteding aan die onderwys in reële terme soos volg toegeneem.

Tabel 1. Onderwysbegroting 1985 tot 1990

\begin{tabular}{|l|c|c|}
\hline Jaar & Onderwysbegroting & \% van totale begroting \\
\hline $1985 / 86$ & R5 110m & 16,2 \\
$1986 / 87$ & R6 204m & 16,2 \\
$1987 / 88$ & R9 222m & 19,7 \\
$1988 / 89$ & R10 264m & 19,1 \\
$1989 / 90$ & R12 027m & 18,9 \\
$1990 / 91$ & R14 541m & 20,3 \\
\hline
\end{tabular}

(DNO, 1991(b): p. 48)

Die staatsbegroting vir die onderwys is in die verlede op ' $n$ oneweredige per capitabasis aan departemente van die verskillende bevolkingsgroepe verdeel. Die regering het hom egter reeds 'n aantal jare gelede verbind tot die uitwissing van diskriminasie op hierdie terrein en om pariteit te bereik sover dit die per capita-toedeling betref Veranderings in hierdie verband blyk uit tabel 2.

Tabel 2. Besteding per leerling

\begin{tabular}{|l|l|l|}
\hline & Blank & Swart \\
\hline $1984 / 85$ & R1 926 & R292 \\
$1988 / 89$ & R3 082 & R764 \\
$1989 / 90$ & R3 536 & R980 \\
\hline
\end{tabular}

(DNO, 1991(b): p. 34)

Dit kan aanvaar word dat finansiële gelykberegtiging in die onderwys een van die sake sal wees waaroor konsensus by KODESA of elders bereik sal word. Daar is natuurlik 
verskillende faktore wat die per capita-bedrag bepaal en wat ook kan bydra tot verskille tussen die bevolkingsgroepe. So is dit byvoorbeeld 'n feit dat blanke onderwysers tans baie beter gekwalifiseerd is as swart onderwysers. Hierdie gegewe beteken dat die salariskomponent van die blanke onderwyskorps per kop heelwat hoër sal wees as dié van swart onderwysers - 'n feit wat meebring dat die per capitatoedeling van die blanke kind groter sal wees as dié van die swart kind. As onderwysers van swart leerlinge ook beter kwalifikasies verwerf, sal die finansiële toedeling vir dié groep per leerling by implikasie ook styg.

As gevolg van die bestaande sosio-ekonomiese strukture kan verwag word dat daar nie baie gou grootskaalse integrasie in woongebiede - en dus in skole - sal wees nie. Dit beteken dat die meeste staatskole vir ten minste die afsienbare toekoms hoofsaaklik uit lede van een bevolkingsgroep sal bestaan. Die kostefaktor van onderwysersalarisse sal na verwagting as gevolg hiervan nog vir 'n taamlike tyd 'n verskil in die per capitatoewysing meebring.

'n Belangrike faktor wat in die finansiële prentjie na vore kom, is die toename in die getalle leerders, wat in 'n groot mate deur 'n hoë fertiliteitsyfer teweeggebring word veral by swartes.

Tabel 3 gee 'n aanduiding van die toename in leerlinggetalle.

Tabel 3. Toename in leerlinggetalle

\begin{tabular}{|l|r|r|r|}
\hline & 1970 & \multicolumn{1}{|c|}{1980} & \multicolumn{1}{|c|}{1990} \\
\hline Blankes & 854413 & 1117280 & 971587 \\
Swartes & 1846190 & 3150948 & 5484998 \\
Kleurlinge & 515508 & 759275 & 847647 \\
Indiërs & 163325 & 217580 & 242323 \\
Totaal & 3379636 & 5245083 & 7546555 \\
\hline
\end{tabular}

(Saamgestel uit DNO, 1990; RSA, 1988; RSA, 1991.)

In 1990 alleen het omtrent 325000 bykomende swart skoliere tot die onderwys toegetree (DNO, 1991(c)), 'n toename wat 'n verdere 325 skole van 1000 leerlinge elk vereis.

Dit moet in gedagte gehou word dat onderwys vir blankes verpligtend is en dat aanvaar kan word dat feitlik $100 \%$ leerpligtige blanke leerlinge reeds vir baie jare by skole 
ingeskryf is. Daarenteen is onderwys vir swart leerlinge nog nie verpligtend nie en is 'n groot deel van die toename in getalle ook toe te skryf aan nuwe skooltoetreders wat nie met aanwas verband hou nie. Verstedeliking van veral swartes is waarskynlik ook 'n belangrike rede waarom meer leerlinge dit tans moontlik vind om wel skole by te woon.

In die 1991-staatsbegroting is 'n bedrag van R16 230 miljoen of $19,1 \%$ van die begroting vir onderwys geoormerk (Anon., 1992:13). In dieselfde jaar was daar 9,93 miljoen leerlinge in gewone staatskole (Transkei, Bophuthatswana, Venda en Ciskei uitgeslote) (DNO, 1991c:8). Indien faktore wat die per capita-toedeling van die verskillende bevolkingsgroepe kan beïnvloed buite rekening gelaat word, beteken dit ' $n$ bedrag van R1 634 per leerling. As hierdie syfers met dié in tabel 2 vergelyk word, blyk dit dat die toedeling per swart leerling heelwat sal verhoog, terwyl dié van die blankes taamlik sal afneem. Ook die per capita-bedrag vir Kleurling-en Indiërleerlinge sal in dié geval afneem.

Wanneer die beskikbare staatsfondse vir onderwys op 'n pariteitsbeginsel verdeel word, sal daar nie voldoende fondse beskikbaar wees om vir meer as sewe jaar staatsgefinansierde onderwys te voorsien nie (vgl. DNO, 1991a:22).

Waarskynlik een van die grootste uitdagings waarvoor die onderwys in Suid-Afrika in die toekoms te staan gaan kom, sal die finansiering van die onderwys, veral in die sekondêre skool, wees. By hierdie dilemma van 'n tekort aan finansiering moet ook nog die heersende inflasiekoers van $15-16 \%$ per jaar in berekening gebring word. Daarvoor moet nou reeds deur ouers, gemeenskappe, firmas, kerke en ander groepe voorsiening gemaak word met behulp van beleggingskemas, trustfondse en op ander finansieringswyses.

Die oorskakeling na die Model $\mathrm{C}$ staatsondersteunde skool en die aanvaarding van hierdie model deur $96 \%$ van die blanke ouers is 'n aanduiding dat daar begrip is vir die finansiële dilemma waarin die staat verkeer en dat daar by die ouers aanvaarding is van die werklikheid dat hulle addisioneel vir die onderwys sal moet bydra.

\section{5. 'N NUUTGESTRUKTUREERDE ONDERWYSSTELSEL}

'n Deel van 'n nuwe staatkundige struktuur is die daarstelling van 'n nuwe onderwysstelsel. Die betrokke partye wat by die staatkundige onderhandelings betrokke is, het reeds laat blyk dat hulle oor sekere breë gedagterigtings saamstem. Daar sal volgens uitsprake waarskynlik een sentrale staatsdepartement vir onderwys wees. Die verwagting is verder dat daar op streeksvlak grootliks 'outonome' uitvoerende onderwys- 
departemente sal wees wat verantwoordelik sal wees vir alle onderwys in die streek.

Afgesien van besonderhede in verband met finansiering, is dit noodsaaklik dat daar oorhoofse koördinering en kontrolering van standaarde, kurrikula en sertifisering sal wees, om enkele van die belangrikste aspekte te noem. Aan die ander kant sal soveel as moontlik besluitneming afgewentel moet word na die streeksdepartemente en selfs tot by die plaaslike skoolgemeenskap.

Die plaaslike gemeenskap sal voor die uitdaging gestel word om verantwoordelikheid te aanvaar vir die kwaliteit van onderwys wat die leerlinge ontvang sover dit bepaal word deur die gehalte professionele diens van die onderwyser, onderwysfasiliteite en onderwysgeleenthede.

'n Gemeenskap sal moet aanvaar dat die leerlinge die gehalte onderwys sal ontvang waarvoor die ouers bereid is om verantwoordelikheid te aanvaar. Ten diepste kom dit neer op die waarde wat ouers aan die onderwys heg.

Presies hoe die struktuur van die onderwys in die toekoms daar sal uitsien, is op hierdie stadium nie duidelik nie. Dit moet egter aanvaar word dat staatskole deur leerlinge van alle bevolkingsgroepe bygewoon sal (kan) word. Die persentasie leerlinge van elke bevolkingsgroep sal waarskynlik bepaal word deur die samestelling van die skool se voedingsgemeenskap en die moontlike toevloei van leerlinge uit ander gebiede - vir watter rede ook al.

Die feit dat 'n skool se leerlinge in die toekoms meer heterogeen sal wees, sal ook bepaalde eise aan die onderwysers stel. Leerlinge met verskillende kultuuragtergronde sal in dieselfde klas wees, hulle sal die leerinhoude verskillend ervaar en verskillend beoordeel, daar sal groter verskille in prestasievlakke wees en die kulturele en sosioekonomiese situasie van die ouers sal meer uiteenlopend wees as tans. Hierdie interkulturele en multikulturele situasies sal deur die onderwysers en die ouergemeenskap geakkommodeer moet word.

Die finansiering van 'n onderwysstelsel wat sy beslag hoofsaaklik op streeksvlak kry, sal ook eiesoortige probleme lewer. Indien aanvaar word dat 'n finansieringsbeleid gevolg gaan word wat min of meer vergelyk kan word met dié van die VSA, beteken dit dat die sentrale regering 'n bepaalde bedrag aan die streeksregering sal oorbetaal, wat dit dan deur middel van streeksheffings of belastings moet aanvul. Dit kan dus gebeur dat daar verskille in die onderwysfinansiering van die verskillende streke sal wees. 


\section{ONDERWYSSTANDAARDE}

Een van die grootste probleme in 'n toekomstige onderwysbestel sal die handhawing van standaarde wees. Standaarde beteken hier veral akademiese en professionele standaarde.

Daar word nou reeds deur sommige politici beweer dat die propagering van die handhawing van standaarde ' $n$ poging is om onderwys eksklusief te maak en om bepaalde leerlinge onderwys te ontsê. Die handhawing van akademiese standaarde is egter 'n sine qua non vir die behoud van 'n aanvaarbare lewenspeil en vir die lewering van skoolverlaters wat in staat is tot sinvolle beroepsopleiding en taakvervulling. Om die onderwysstandaard te verlaag sodat meer leerlinge sertifikate kan verwerf, sal nie bydra om die algemene peil van akademiese skoling te handhaaf nie

Die kwaliteit en standaard van die onderwys word in 'n groot mate bepaal deur die persoonlike en professionele kwaliteit van die onderwyser. Daar is tans groot verskille ten opsigte van die vlak van opleiding tussen onderwysers van die verskillende bevolkingsgroepe. In 1989 het $45 \%$ van die swart onderwysers byvoorbeeld nie oor die basiese onderwyserskwalifikasie van matriek plus drie jaar opleiding beskik nie (DNO, 1991c:12). Vanselfsprekend is die opleidingpeil van die onderwyser 'n belangrike faktor in die leerling se akademiese vorming.

Onderwysersopleiding - en veral die opleiding van swart onderwysers - sal in die toekoms hoë voorkeur moet geniet. Die RGN-ondersoek na die onderwys (die sogenaamde De Langeverslag van Julie 1981) het reeds tien jaar gelede die belangrikheid van hierdie behoefte uitgewys. Om kwaliteitonderwys deur swart onderwysers op groter skaal beskikbaar te stel sal baie meer onderwysers uit hierdie groep hoëvlakopleiding moet ontvang.

' $n$ Tweede belangrike faktor wat standaarde in die onderwys bepaal, is die leerling en die onderwyser se siening van die waarde van onderwys. Waar daar deur leerlinge en onderwysers 'n hoë premie op onderwys geplaas word, gaan dit goed met die onderwys - dikwels ten spyte van 'n gebrek aan middele. 'n Voorbeeld hiervan is die algemene rehabilitasie van die Afrikaner ná die Anglo-Boere-oorlog en ook ná die depressie van 1933. Getuienis daarvan is volop in die internasionale wêreld. Maar ook in SuidAfrika is voorbeelde bekend van skole vir swart leerlinge wat 'n sterk leerkultuur handhaaf en goeie standerd-tienuitslae behaal midde in 'n situasie waar die algemene slaagsyfer nie veertig persent haal nie. Voorbeelde hiervan is in die dagbladpers beskrywe. 
Die handhawing van 'n hoë professionele etiese kode is 'n noodsaaklike voorwaarde vir die handhawing van algemene onderwysstandaarde. 'n Professionele liggaam wat professionele dissipline kan toepas is in alle professies 'n vereiste. Onderwysers wie se persoonlike lewenstyl in botsing is met opvoedingsbeginsels moet uit die professie geweer word. Stakings, laksheid, die aanblaas van geweld en ander soortgelyke optredes deur onderwysers sal ter wille van die behoud van gehalte-onderwys en -opvoeding onverbiddelik as onprofessionele optrede behandel moet word.

Ten spyte van wat tans in die praktyk gebeur (naamlik die uitskakeling van blanke onderwysers in skole vir swartes) is goedopgeleide onderwysers in blanke geledere 'n waardevolle bron van professionele kragte vir leerlinge van elke bevolkingsgroep. Hierdie bron behoort om suiwer opvoedkundige redes ten volle benut te word solank dit nodig is.

'n Probleem wat ten nouste met die handhawing van akademiese standaarde saamhang, is die bevordering van leerlinge van een standerd na die volgende sonder dat die vereiste standaard behaal is. Die kumulatiewe uitwerking van hierdie praktyk is dat ' $n$ leerling se agterstand al groter word en sy kanse om later 'n eksterne eksamen te slaag al kleiner word. Die toepassing van akademiese standaarde vir die bevordering van leerlinge van een standerd na die volgende sal veral vir swart leerlinge van belang wees. Dit sal ook die slaagsyfer in st. 10 positief beïnvloed, veral as in gedagte gehou word dat die helfte van 1990 se swart st. 10-kandidate slegs 'n gemiddelde van $29 \%$ kon haal (DNO, 1991c:10).

\section{ONDERWYS OP GROND VAN ERKENDE OPVOEDKUNDIGE BEGINSELS}

Onderwys in Suid-Afrika is, ten regte of ten onregte, verstrengel met die politiek. Tog moet 'n mens probeer om sekere sake wat lyk of dit 'n uitgesproke politieke kleur het, om opvoedkundige redes duidelik uit te lig. Die belangrikstes hiervan is die taalmedium, die gees en karakter van die skool, die kultuur van die ouerhuis en ouerbetrokkenheid.

In Suid-Afrika is die taalmedium of voertaalkwessie reeds vir baie jare 'n bron van konflik. In die geskiedenis van die Boererepublieke, tydens en net na die Tweede Wêreldoorlog en in 1976 met die Soweto-opstande, staan die voertaalkwessie sentraal in die fokus (Hartshorne, 1992:186).

Dit word wêreldwyd aanvaar dat dit opvoedkundig die beste is as die kind in sy moedertaal onderrig ontvang. Vanselfsprekend kan daar redes wees wat meebring dat meer gevorderde onderwys nie in die moedertaal kan plaasvind nie, byvoorbeeld as die 
taal (nog) nie gesofistikeerd genoeg is om as akademiese taal gebruik te kan word nie, of as handboeke en ander onderrigmateriaal nie in die taal beskikbaar is nie. Maar selfs in sulke omstandighede behoort die kind so ver as moontlik in sy moedertaal as medium van onderrig onderwys te ontvang.

Tot in April 1992 was die reëling in verband met die voertaal in die onderwys vir swartes dat leerlinge in Sub. A tot st. 2 onderwys in hulle moedertaal ontvang en daarna in die taal van die ouers se keuse (Wet 90 van 1979, soos gewysig). Hierdie keuse was feitlik sonder uitsondering Engels. Die promulgering van die Wysigingswet op Onderwys en Opleiding, (Wet 100 van 1991) en die afkondiging van die proklamasie van die Staatspresident op 30 April 1992 (Suid-Afrika, 1992) bring mee dat ouers van swart leerlinge tans geraadpleeg word oor die medium van onderrig waarin hulle kinders vanaf Sub. A onderwys moet ontvang.

Ten opsigte van die gees en karakter van die skool is dit veral die skole met 'n sterk Westerse inslag, byvoorbeeld Afrikaanse, Engelse en Duitse (privaat) skole, wat reeds deur die loop van jare 'n eie unieke karakter ontwikkel het. Hierdie eie karakter van elke skool is die resultaat van die invloede van die onderwyskorps (dikwels veral die persoonlikheid van die skoolhoof), die besondere ouergemeenskap, die leerlinge en die oudleerlinge. Prestasies en houdings van leerlinge van die skool word meestal sterk gemotiveer deur tradisies en die gees en karakter van die skool.

Vir algemene opvoedende onderwys is die opbou van 'n gesonde trots vir sy skool se naam 'n belangrike onderbou van 'n leerling se toerusting. In 'n nuwe onderwysopset sal gepoog moet word om elke skool in staat te stel om sy etos te handhaaf, en waar dit in baie gevalle nog grootliks ontbreek, te bou en te ontwikkel.

Die kultuur van die ouerhuis waaruit 'n skool sy leerlinge trek, bepaal in 'n groot mate die gees en karakter van die skool. Belangrike elemente waaruit hierdie kultuur saamgestel is, is die religieuse beskouings van die kollektiewe ouerkorps, die norme en waardes, die maatskaplike gebruike en die tradisies van die ouergemeenskap. 'n Skool wat opvoedende onderwys verskaf, kan nie 'n kleurlose, neutrale plek wees waar leerinhoude bloot oorgedra word nie; dit druis in teen die wese van die skool.

Die handhawing van 'n bepaalde gees en karakter, of die opbou daarvan, gaan in die toekoms groot uitdagings stel aan die onderwysers, leerlinge en ouers van skole wat in 'n groot mate multikultureel is.

Ouerbetrokkenheid by die onderwys het in die verlede nie hoë prioriteit geniet by of die onderwysowerhede of die ouergemeenskap self nie. Tog is dit deur navorsing bewys dat die mate waarin 'n leerling se ouers by die skool betrokke is positief korreleer met 
die kind se skoolprestasie. Verder is dit ook so dat 'n ouerkorps wat aktief deelneem aan die bedrywighede van die skool 'n groot bate vir die skool is. In die nuwe ontwikkelinge op onderwysgebied word ouerbetrokkenheid veral om finansiële redes belangrik, omdat ouers waarskynlik deur die bank addisionele bydraes tot hulle kinders se onderwys sal moet maak. Soos tans die geval is by staatsondersteunde skole van die Departement van Onderwys en Kultuur (Administrasie: Volksraad) sal ouers wat substansiële bydraes moet maak, ook veel groter bestuursbevoegdhede kry. Die kundigheid om hierdie bestuursverantwoordelikhede behoorlik na te kom, ontbreek nog op baie plekke. Verteenwoordigers van ouergemeenskappe - en in baie gevalle ook onderwyspersoneel - sal geskool moet word om die nuwe situasie te hanteer.

Daar is in Suid-Afrika nie ' $n$ tradisie van grootskaalse ouerbetrokkenheid nie - met enkele klein uitsonderings. Tog sal die nuwe situasie in die onderwys in 'n groot mate bepaal word deur die omvang en kwaliteit van die ouers se deelname aan die finansiering, bestuur en beheer van die onderwys. Dit is terselfdertyd die bereiking van 'n ideaal en 'n groot uitdaging.

\section{SAMEVATTING}

Die ontwikkeling van die onderwys in Suid-Afrika het in 'n groot mate die spoor van die staatkundig-maatskaplike strukture gevolg. Dit was die rede waarom daar'n hele aantal onderwysdepartemente vir die verskillende bevolkingsgroepe ontstaan het. Sedert 2 Februarie 1990 is 'n nuwe staatkundige koers deur die regering ingeslaan wat ook vir die onderwyssituasie belangrike betekenis het en nuwe uitdagings aan die rolspelers in die onderwys gaan stel. Nuwe finansiële eise sal verreken moet word, daar sal vir meer leerlinge onderwys verskaf moet word en onderwysstandaarde sal gehandhaaf moet word.

'n Paar kernpunte waar die uitdagings van 'n nuwe onderwyssituasie die sterkste ervaar sal word, is die kwessie van die voertaal in die onderwys, die daarstelling en handhawing van 'n eie gees en karakter vir elke skool, in harmonie met die kultuur van die gemeenskap, en veel groter ouerbetrokkenheid by en verantwoordelikheid vir die onderwys van die kind.

\section{BIBLIOGRAFIE}

ANON. 1992. Oop hand vir onderwys. Finansies en Tegniek: 13, Maart 20.

DEPARTEMENT VAN NASIONALE OPVOEDING. 1991a. 'n Kurrikulummodel vir onderwys in Suid-Afrika. Besprekingsdokument van die Komitec van Onderwysdepartementshoofde. Pretoria. 
DEPARTEMENT VAN NASIONALE OPVOEDING. 1991b. Onderwysrealiteite in Suid-Afrika. 1990. Verslag. Nasop. 02- 300 (91/06). Pretoria.

DEPARTEMENT VAN NASIONALE OPVOEDING. 1991c. Onderwysvernuwing-strategie (OVS). Besprekingsdokument. Pretoria.

DEPARTEMENT VAN NASIONALE OPVOEDING. 1990. Voorlopige onderwys-statistiek vir 1990. Verslag. Nasop 02-214 (90/08). Pretoria.

DEPARTEMENT VAN NASIONALE OPVOEDING. 1992. Voorlopige onderwys-statistiek vir 1992. Verslag. Nasop 02-214 (92/07). Pretoria.

DNO. Kyk Departement Nasionale Opvoeding.

DOK. Kyk Departement van Onderwys en Kultuur. (Administrasic. Volksraad)

DU PLESSIS, A., DU PISANI T. \& TEN PLEKKER, S.J. 1990. Education and Manpower Development 1989. Rescarch Institute for Education Planning. Blocmfontein : University of the Orange Free State.

HARTSHORNE, K. 1992. Crisis and Challenge. Black Education 1910-1990. Cape Town : Oxford University Press.

REPUBLIEK VAN SUID-AFRIKA. 1991. Suid-Afrikaanse Arbeidstatistiek. (1970-1990). Pretoria : Sentrale Statistickdiens.

REPUBLIEK VAN SUID-AFRIKA. 1988. Suid-Afrikaanse Statistick. (1970-1987). Pretoria : Sentralc Statistickdiens.

RSA. Kyk Republick van Suid-Afrika

SUID-AFRIKA (REPUBLIEK), 1967. Wet op Onderwysbeleid, no, 39 van 1967. Pretoria : Staatsdrukker.

SUID-AFRIKA (REPUBLIEK). 1979. Wet op Onderwys en Opleiding, no. 90 van 1979. Pretoria Staatsdrukker.

SUID-AFRIKA (REPUBLIEK). 1983. Grondwet van die Republick van Suid-Afrika, no. 110 van 1983. Pretoria : Staatsdrukker.

SUID-AFRIKA (REPUBLIEK). 1984. Wet op Nasionale Beleid vir Algemene Onderwyssake, no. 76 van 1984. Pretoria : Staatsdrukker.

SUID-AFRIKA (REPUBLIEK). 1988. Wet op Onderwysaangeleenthede (Volksraad), no. 70 van 1988. Pretoria : Staatsdrukker.

SUID-AFRIKA (REPUBLIEK). 1991. Wysigingswet op Onderwys en Opleiding, no. 100 van 1991 Prctoria : Staatsdrukker.

SUID-AFRIKA (REPUBLIEK), 1992. Regulasies in verband met medium van onderrig. (Proklamasic no. R37, 1992.) Staatskoerant, 4860:3-5. A pril, 30. 